\title{
Epithelial to mesenchymal transition in tumor cells as consequence of phenotypic instability
}

\section{Antonio García de Herreros*}

Programa de Recerca en Càncer, Departament de Ciències Experimentals i de la Salut, Institut Hospital del Mar d'investigacions Mèdiques, Universitat Pompeu Fabra, Barcelona, Spain

\section{Edited by:}

Pierre Savagner, Institut National de la Santé et de la Recherche

Médicale, France

Reviewed by:

Navneet Momi, Boston Medical Center, USA

Pierre Savagner, Institut National de la Santé et de la Recherche

Médicale, France

*Correspondence:

Antonio García de Herreros, Departament de Ciències

Experimental i de la Salut, Parc de Recerca Biomèdica de Barcelona,

IMIM, Doctor Aiguader 88, 08003

Barcelona, Spain

e-mail:agarcia@imim.es
During the last years many articles have reported epithelial-to-mesenchymal transitions (EMT) induced by a myriad of gene products either when added to the cell medium or when transfected. Molecularly the EMT is characterized by the up-regulation of transcriptional factors (EMT-TFs) repressing the epithelial gene E-cadherin, a protein essential for the maintenance of the epithelial phenotype. These EMT-TFs are subjected to a complex regulation involving binary self-stimulatory loops, allowing the possibility of the amplification of input signals. The capability of EMT-TFs to promote an EMT is controlled by E-cadherin that limits the transcription of mesenchymal genes. We discuss here the differences between normal and tumor epithelial cells; in the latter a partial inactivation of E-cadherin function enables extracellular signals to be amplified and induce an EMT. This tumor cell phenotypic instability is exacerbated in cell culture conditions. Therefore, it is likely that many of the gene products reported to control this transition act only in very specific cell tumor cell lines; thus, in cells with an unstable phenotype due to pre-existing alterations in E-cadherin safeguard mechanism.

\section{Keywords: EMT, Snail1, E-cadherin, self-amplification, tumor instability}

\section{TRANSCRIPTIONAL FACTORS CONTROL EMT}

Epithelial to Mesenchymal transition (EMT) was initially described by Elizabeth Hay decades ago (Hay, 1968); in the 80's and 90 's several groups reported the acquisition of a fibroblastic, scattered or undifferentiated phenotype after prolonged treatments of epithelial cells with cytokines such as TGF- $\beta$. EMT is characterized by an extensive down-modulation of the key epithelial gene E-cadherin and the induction of mesenchymal markers, such as Fibronectin or Vimentin (Nieto, 2011). However, it was at the beginning of 2000 when EMT started to be widely studied following the description of transcriptional repressors that directly act on E-cadherin gene, inhibiting its expression and inducing the acquisition of a mesenchymal phenotype by epithelial cells (Batlle et al., 2000; Cano et al., 2000; Grooteclaes and Frisch, 2000; Comijn et al., 2001; Hajra et al., 2002; Yang et al., 2004). Among these transcriptional factors, the Snail family, particularly Snaill, has received more attention although the Zeb and Twist families have also been extensively studied. All these factors will be referred below as EMT-related transcription factors (EMT-TFs).

Transfection of Snaill, Zeb1 or Twist1 induces an EMT in most cell lines (Batlle et al., 2000; Cano et al., 2000; Grooteclaes and Frisch, 2000; Comijn et al., 2001; Hajra et al., 2002; Yang et al., 2004). When compared, Zeb1 is more potent as E-cadherin repressor whereas Twist induces better mesenchymal genes; Snail1 seems to gather both properties (Garcia de Herreros and Baulida, 2012). Snaill ectopic expression induces Zeb1 expression; however, Zeb1 does not alter Snaill levels which suggests that Zeb1
(Nieto, 2011) is downstream Snaill in the signaling pathway controlling EMT (Garcia de Herreros and Baulida, 2012). Twist and Snaill seem to reside in parallel branches since only very occasionally they activate each other (at least transcriptionally), although both cooperatively induce Zeb1 (Dave et al., 2011). The complementary role of both factors is also demonstrated by developmental studies indicating that during gastrulation Twist hypomorphic mutants are rescued by Snaill overexpression (Wong et al., 2014).

Kinetically Snaill is the first factor to be up-regulated during cytokine-driven g EMT (Peinado et al., 2007). For instance, in the broadly used system of mammary murine NMuMG cells exposed to TGF- $\beta$, Snaill up-regulation is detected as early as $30 \mathrm{~min}$ after TGF- $\beta$ addition whereas Zeb1 or other mesenchymal markers require $4-6 \mathrm{~h}$ and Twist 1 is not consistently increased (Dave et al., 2011). This activation of Snaill protein is transient whereas that of Zeb1 is not. Due to these results Snail1 has been considered as the transcriptional factor triggering EMT, whereas Zeb1 would be responsible for the consolidation of the mesenchymal phenotype by repressing E-cadherin and other epithelial genes (Peinado et al., 2007; Garcia de Herreros and Baulida, 2012).

The EMT-TFs present common features. For instance all Snail1/2, Zeb1/2 and Twist are very unstable proteins with halflives around $30 \mathrm{~min}$ (Diaz et al., in press). Different ubiquitin ligases have been characterized acting specifically on one, two, or even three of these factors (Diaz et al., in press); therefore, downregulation of these ubiquitin ligases is capable to trigger EMT (Viñas-Castells et al., 2014; Zheng et al., 2014). 


\section{SIGNALING PATHWAYS CONTROLLING EMT SHOW POSITIVE AND NEGATIVE FEED-BACK LOOPS}

EMT-TFs gene expression is dependent on the activity of several common and ubiquitous transcriptional factors, such as NF$\kappa \mathrm{B}, \beta$-catenin/Tcf-4 and Ets-2 (Garcia de Herreros and Baulida, 2012; De Craene and Berx, 2013). Since activation of these factors can be achieved by several extracellular cues, it should be expected that EMT is induced by these signals although this is not the case; for instance Snail 1 transcription can be up-regulated by factors, such as TNF $\alpha$ or Wnt3a, that normally do not promote an EMT. It is possible that the extent, or more likely the continuity, of the stimulation might be relevant and a persistent up-regulation, for instance in $\beta$-catenin/Tcf- 4 transcriptional activity, might promote an EMT. Alternatively, this transition might also require the convergence of signals acting on two of these transcriptional complexes, or the activation of not only the transcription but also the stabilization of key genes such as Snaill. This can also apply to some other levels of control since the mRNA stability of many EMT-TFs is also controlled by miRNAs.

Moreover, the study of the transduction pathways controlling the expression of EMT-TFs has revealed that these pathways are not linear but display numerous points of self-control either positive or negative. It has been demonstrated the existence of binary circuits composed by two genes that negatively regulate each other; for instance in the systems miR-34a/Snaill and miR-200/Zeb1, the EMT-TF inhibits the miRNA acting on the same TF (Bracken et al., 2008; Burk et al., 2008; Kim et al., 2011; Siemens et al., 2011) (Figure 1). This creates a positive feed-back loop since increases in Snaill, for instance, inhibits its repressor miR-34a and further stimulates Snaill mRNA stability. Other examples are provided by the action of the transcriptional complexes mentioned above; stimulation of the canonical Wnt pathway induces the repression of E-cadherin through the stimulation of $\beta$-catenin/TCF- 4 dependent-EMTTFs (such as Zeb1), releasing more $\beta$-catenin and enhancing the activity of this transcriptional complex, therefore amplifying the initial signal (Garcia de Herreros and Baulida, 2012). On the contrary, Snaill also represses its own synthesis, either by direct binding to SNAIL promoter or by blocking the activity of Egr-1, a Snail1-gene transcriptional activator (Grotegut et al., 2006; Peiro et al., 2006). A theoretical analysis of these circuits has suggested that the EMT process is bi-stable, and an intermediate epithelial-mesenchymal hybrid phenotype also presents stability (Lu et al., 2014). Another study using human breast epithelial MCF10A cells treated with TGF- $\beta$ also describe the existence of this intermediate phenotype that, contrarily to the full mesenchymal state, is reversible upon elimination of the cytokine (Zhang et al., 2014). The existence of this partial EMT is consistent with observations in carcinomas where co-expression of epithelial and mesenchymal markers has been detected in the same cells. However, in most tumors this intermediate phenotype looks much more epithelial than mesenchymal and maintains most of the epithelial structures, which suggests that the balance is biased toward the epithelium linage.
Self-inhibition
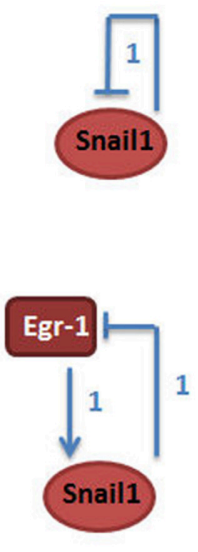

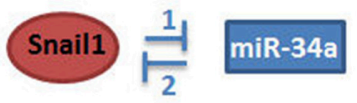

$1,3,4$

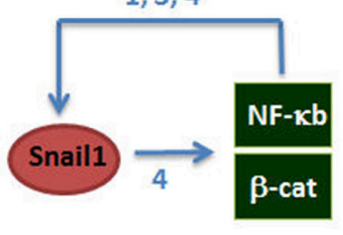

1

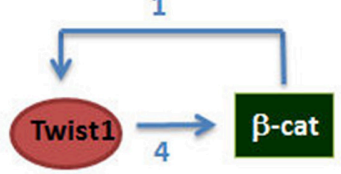

Zeb1

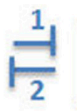

miR-200b

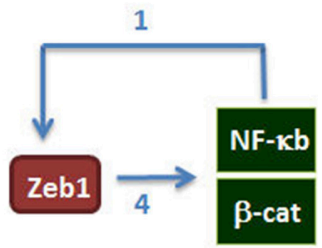

1

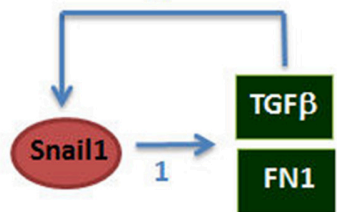

Control: 1, Transcriptional; 2, RNA stability; 3, Protein stability; 4, Protein localization

FIGURE 1 | EMT-TFs are controlled by self-inhibition and self-activation. The figure shows examples of mechanisms of self-inhibition (left) or activation (right) controlling the expression of Snail1, Twist1, and Zeb1. The number indicates the type of control. Besides the references indicated in the text, the mechanisms shown in this figure are documented in Howe et al. (2003), Barberà et al. (2004), Bachelder et al. (2005), Yook et al. (2006), Julien et al. (2007), Stemmer et al. (2008), Kudo-Saito et al. (2009), Wu et al. (2009), Sánchez-Tillo et al. (2011). 


\section{E-CADHERIN PROTEIN PROTECTS FROM EMT}

The most relevant gene product for the maintenance of the epithelial phenotype is E-cadherin. As it is well known, E-cadherin is required for the formation of adherens junction; however its role is not limited to this since it binds and restrains the transcriptional activity of $\beta$-catenin (Valenta et al., 2012) that, as commented above, is required for the expression of EMT-TFs. A similar negative action of E-cadherin has also been reported on NF- $\kappa b$ activity (Kuphal et al., 2004; Solanas et al., 2008). Although in this case the biochemical basis is not well characterized it relies in the interaction of NF-kB with the adherens junction complex (Deng et al., 2002; Solanas et al., 2008). This E-cadherin role limiting the transcriptional role of $\beta$-catenin, NF- $\kappa$ B and perhaps Ets-2 is essential for the control of EMT and the activity of EMT-TFs. Accordingly, E-cadherin ectopic expression prevents the induction of mesenchymal genes in several models of EMT (Ohkubo and Ozawa, 2003; Solanas et al., 2008). Although it is not sufficient by itself, since only very occasionally E-cadherin down-regulation induces mesenchymal markers, the decrease in the levels or function of this protein is absolutely necessary for a full EMT. As we present in our model, shown in Figure 2, cells presenting static adherens junctions are not receptive for signals promoting an EMT. Although Snaill is induced and eventually down-regulate E-cadherin gene transcription, since E-cadherin protein when present in the adherens junction is protected from degradation (Gumbiner, 2005), this Snaill-induced mRNA decrease will not be translated in a down-regulation in E-cadherin protein. In addition, the stable junctional complexes retain $\beta$-catenin and NF-kB and restrain their traffic to the nucleus and their transcriptional activity on mesenchymal genes (Kuphal et al., 2004; Solanas et al., 2008). Therefore, E-cadherin acts as safeguard of the epithelial phenotype preventing transient signals to be amplified and promote undesired EMT. Thus, this transition will require additional signals that decrease adherens junction stability and make cells receptive to EMT-TFs action.

\section{TUMOR CELLS ARE PRONE TO EMT}

Accordingly, it is expected that epithelial cancer cells will be much more susceptible to EMT than non-transformed epithelium (Figure 2). Total or partial loss of adherens junctions is a common alteration in neoplastic cells normally due to posttranslational modifications of E-cadherin-associated proteins; for instance $\beta$-catenin tyrosine phosphorylation decreases its interaction with E-cadherin and causes adherens junction instability

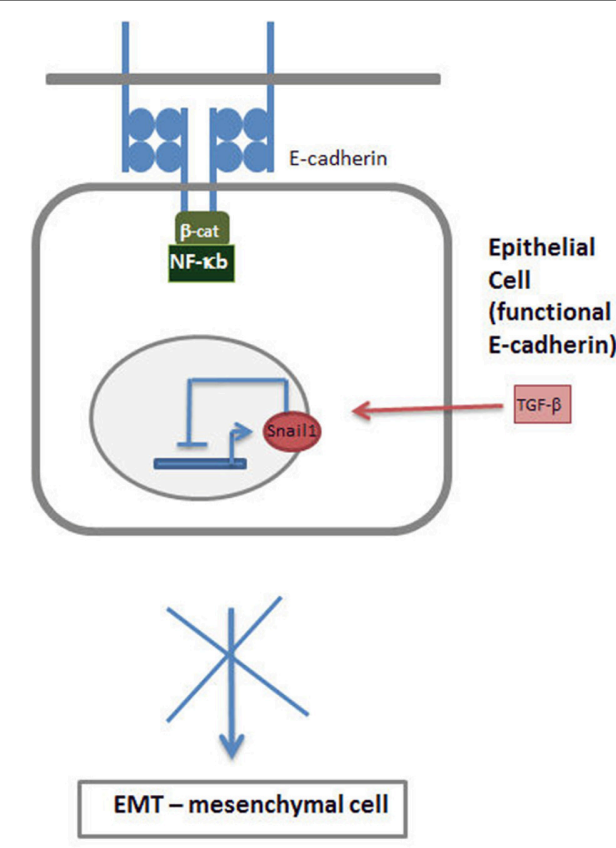

FIGURE 2 | Tumor cells are more receptive to signals inducing EMT. According to our model, an epithelial cell with functional E-cadherin and stable adherens junctions is not sensitive to extracellular signals inducing Snail1 and EMT such as TGF- $\beta$ (left). Although these cytokines activate Snail1 expression, due to the high stability of E-cadherin protein the down-regulation in E-cadherin mRNA is not translated in changes in the protein. Moreover, stable junctional complexes retain $\beta$-catenin and NF-kB restrained their traffic to the nucleus and transcriptional activity. In these conditions Snail1 expression is self-inhibited and the EMT process is not initiated. Tumor epithelial cells contain less static adherens junctions due to post-translational

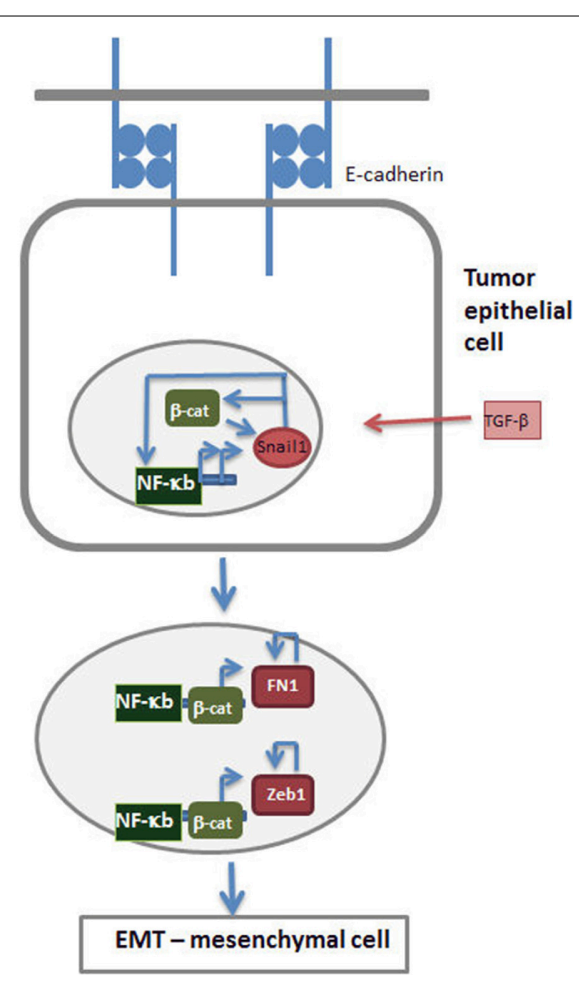

modifications of E-cadherin or associated proteins, such as $\beta$-catenin; consequently the stability of E-cadherin protein is lower. In these conditions Snail1 increases do cause a significant down-modulation in E-cadherin protein and facilitates the traffic of NF-kB ad $\beta$-catenin to the nucleus and the activation of their transcriptional activity. These two factors further stimulate Snail1 expression, either by directly stimulating Snail gene transcription (NF-kB) or increasing protein stability (NF-אB, $\beta$-catenin), therefore amplifying the initial signal. Moreover, they also up-regulate the transcription of other mesenchymal markers such as Zeb1 or fibronectin (FN1), triggering a self-stimulatory circuit described in Figure $\mathbf{1}$ and supporting the EMT. 
(Lilien and Balsamo, 2005). This modification is induced by ras or growth factor receptors, elements of a pathway commonly activated in many types of cancers. Moreover, other signaling pathways can weaken E-cadherin with p-120-catenin and favors E-cadherin degradation (Kourtidis et al., 2013). Therefore, transformed epithelial cells can be considered as "primed" epithelial cells capable to respond to cytokines such as TGF- $\beta$ initiating an EMT.

Cell culture studies add a further level of instability to the phenotype. Tumor cell lines are normally cultured in the presence of high serum concentration, a condition that stimulates growth factor receptors. In these conditions many cells do not form compact colonies, at least at low confluence what makes adherens junctional complexes more unstable. Actually, Snail1induced EMT is much more rapid and complete when cells are cultured at low confluence since the effect of this TF is much more rapidly translated in changes in E-cadherin protein levels. Even without additional signals, the phenotype of some tumor cells within the intermediate state is very much dependent on the confluence showing an epithelial morphology at high density and a more mesenchymal one at low confluence (Conacci-Sorrell et al., 2003).

Therefore, it is likely that many of the factors reportedly involved in the control of EMT have only an effect restricted to specific tumor cells presenting a partially inactivated E-cadherin and likely accumulating other alterations. Due to their intrinsic genomic instability, tumor cells might have alterations in genes controlling the EMT-TFs; for instance, a mutation in one of the ubiquitin ligases controlling Snail1 might enhance Snaill upregulation by factors activating Snaill transcription. Once Snail1 have reached a threshold, the EMT process would be amplified by the self-stimulatory circuits and the loss of safeguard mechanisms. These alterations can affect to the many gene products acting on the different levels of control of EMT; thus on EMTTFs transcription, mRNA stability or protein half-life. Thus, tumor cells would not just present genetic but also phenotypic instability, an alteration exacerbated in culture conditions.

Another interesting point is the discrepancy between the results obtained in vitro, in cell lines, showing that EMT is induced by many different conditions and factors, and in vivo, in human tumors, where few cells are detected that have undergone or are in the process of undergoing an EMT (Thompson et al., 2005). It is possible that in human tumors the cellular conditions (cell to cell contacts, composition of tumor stroma) do not enable a full EMT and most cells only respond partially to the same conditions than in vitro promote a very extensive transition. In any case, this partial EMT obtained in vivo might result in the acquisition of some mesenchymal markers and increased invasion maintaining most of epithelial features. It is expected that this EMT is more easy to be observed in the tumor border, where epithelial cell-to-cell interactions are more relaxed due to fewer physical constrains and also to the existence of extracellular cues provided by stromal cells.

Therefore, although nothing can be dismissed in cancer, it is likely that many of the described regulators of EMT present a very limited relevance in vivo. The physiological implication of the many proteins reported to be involved in EMT requires further investigation, not limited to a specific cell line in culture but to animal models or at least to a panel of cell lines. This would allow unveiling the most relevant gene products involved in the control of this essential cellular conversion.

\section{ACKNOWLEDGMENTS}

Work in Antonio García de Herreros laboratory is supported by la Fundación Científica de la Asociación Española contra el Cáncer, Ministerio de Ciencia y Tecnología (SAF2013-48849-C21-R), Fundació La Marató de TV3, Fundación Rodríguez-Pascual and ISCIII/FEDER (RD12/0036/0005).

\section{REFERENCES}

Bachelder, R. E., Yoon, S. O., Franci, C., de Herreros, A. G., and Mercurio, A. M. (2005). Glycogen synthase kinase-3 is an endogenous inhibitor of Snail transcription: implications for the epithelial-mesenchymal transition. J. Cell Biol. 168, 29-33. doi: 10.1083/jcb.200409067

Barberà, M. J., Puig, I., Dominguez, D., Julien-Grille, S., Guaita-Esteruelas, S., Peiro, S., et al. (2004). Regulation of Snail transcription during epithelial to mesenchymal transition of tumor cells. Oncogene 23, 7345-7354. doi: 10.1038/sj.onc. 1207990

Batlle, E., Sancho, E., Franci, C., Dominguez, D., Monfar, M., Baulida, J., et al. (2000). The transcription factor snail is a repressor of E-cadherin gene expression in epithelial tumour cells. Nat. Cell Biol. 2, 84-89. doi: 10.1038/35000034

Bracken, C. P., Gregory, P. A., Kolesnikoff, N., Bert, A. G., Wang, J., Shannon, M. F., et al. (2008). A double-negative feedback loop between ZEB1-SIP1 and the microRNA-200 family regulates epithelial-mesenchymal transition. Cancer Res. 68, 7846-7854. doi: 10.1158/0008-5472.CAN-08-1942

Burk, U., Schubert, J., Wellner, U., Schmalhofer, O., Vincan, E., Spaderna, S., et al. (2008). A reciprocal repression between ZEB1 and members of the miR-200 family regulates epithelial-mesenchymal transition. EMBO Rep. 9, 582-589. doi: 10.1038/embor.2008.74

Cano, A., Perez-Moreno, M. A., Rodrigo, I., Locascio, A., Blanco, M. J., del Barrio, M. G., et al. (2000). The transcription factor snail controls epithelialmesenchymal transitions by repressing E-cadherin expression. Nat. Cell Biol. 2, 76-83. doi: 10.1038/35000025

Comijn, J., Berx, G., Vermassen, P., Verschueren, K., van Grunsven, L., Bruyneel, E., et al. (2001). The two-handed E box binding zinc finger protein SIP1 downregulates E-cadherin and induces invasion. Mol. Cell 7, 1267-1278. doi: 10.1016/S1097-2765(01)00260-X

Conacci-Sorrell, M., Simcha, I., Ben-Yedidia, T., Blechman, J., Savagner, P., and Ben-Ze'ev, A. (2003). Autoregulation of E-cadherin expression by cadherin-cadherin interactions: the roles of beta-catenin signaling, slug, and MAPK. J. Cell Biol. 163, 847-857. doi: 10.1083/jcb.200308162

Dave, N., Guaita-Esteruelas, S., Gutarra, S., Frías, A., Beltran, M., Peiró, S., et al. (2011). Functional cooperation between snaill and twist in the regulation of ZEB1 expression during epithelial to mesenchymal transition. J. Biol. Chem. 286, 12024-12032. doi: 10.1074/jbc.M110.168625

De Craene, B., and Berx, G. (2013). Regulatory networks defining EMT during cancer initiation and progression. Nat. Rev. Cancer 13, 97-110. doi: $10.1038 / \mathrm{nrc} 3447$

Deng, J., Miller, S. A., Wang, H. Y., Xia, W., Wen, Y., Zhou, B. P., et al. (2002). beta-catenin interacts with and inhibits NF-kappa B in human colon and breast cancer. Cancer Cell 2, 323-334. doi: 10.1016/S1535-6108(02)00154-X

Diaz, V. M., Viñas-Castells, R., and García de Herreros, A. (in press). Regulation of the protein stability of EMT transcription factors. Cell Adh Migrat. doi: 10.4161/ 19336918.2014.969998

Garcia de Herreros, A., and Baulida, J. (2012). Cooperation, amplification and feed-back in epithelial-mesenchymal transition. Biochim. Biophys. Acta. 1825, 223-228. doi: 10.1016/j.bbcan.2012.01.003

Grooteclaes, M. L., and Frisch, S. M. (2000). Evidence for a function of CtBP in epithelial gene regulation and anoikis. Oncogene 19, 3823-3828. doi: 10.1038/sj.onc.1203721

Grotegut, S., von Schweinitz, D., Christofori, G., and Lehembre, F. (2006). Hepatocyte growth factor induces cell scattering through MAPK/Egr-1mediated upregulation of Snail. EMBO J. 25, 3534-3545. doi: 10.1038/sj.emboj. 7601213 
Gumbiner, B. M. (2005). Regulation of cadherin-mediated adhesion in morphogenesis. Nat. Rev. Mol. Cell Biol. 6, 622-634. doi: 10.1038/nrm1699

Hajra, K. M., Chen, D. Y., and Fearon, E. R. (2002). The SLUG zinc-finger protein represses E-cadherin in breast cancer. Cancer Res. 62, 1613-1618.

Hay, E. D. (1968). "Organization and fine structure of epithelium and mesenchyme in the developing chick embryo," in Epithelial Mesenchymal Interactions, eds R. Fleischmajer and R. E. Billingham (Baltimore: Williams \& Wilkins), 31-55.

Howe, L. R., Watanabe, O., Leonard, J., and Brown, A. M. (2003). Twist is up-regulated in response to Wnt 1 and inhibits mouse mammary cell differentiation. Cancer Res. 63, 1906-1913.

Julien, S., Puig, I., Caretti, E., Bonaventure, J., Nelles, L., van Roy, F., et al. (2007). Activation of NF-kappaB by Akt upregulates Snail expression and induces epithelium mesenchyme transition. Oncogene 26, 7445-7456. doi: 10.1038/sj.onc. 1210546

Kim, N. H., Kim, H. S., Li, X. Y., Lee, I., Choi, H. S., Kang, S. E., et al. (2011). A p53/miRNA-34 axis regulates snaill-dependent cancer epithelial-mesenchymal transition. J. Cell Biol. 195, 417-433. doi: 10.1083/jcb.201103097

Kourtidis, A., Ngok, S. P., and Anastasiadis, P. Z. (2013). p120 catenin: an essential regulator of cadherin stability, adhesion-induced signaling, and cancer progression. Prog. Mol. Biol. Transl. Sci. 116, 409-432. doi: 10.1016/B978-0-12394311-8.00018-2

Kudo-Saito, C., Shirako, H., Takeuchi, T., and Kawakami, Y. (2009). Cancer metastasis is accelerated through immunosuppression during Snail-induced EMT of cancer cells. Cancer Cell 15, 195-206. doi: 10.1016/j.ccr.2009.01.023

Kuphal, S., Poser, I., Jobin, C., Hellerbrand, C., and Bosserhoff, A. K. (2004). Loss of E-cadherin leads to upregulation of NFkappaB activity in malignant melanoma. Oncogene 23, 8509-8519. doi: 10.1038/sj.onc.1207831

Lilien, J., and Balsamo, J. (2005). The regulation of cadherin-mediated adhesion by tyrosine phosphorylation/dephosphorylation of $\beta$-catenin. Curr. Opin. Cell Biol. 17, 459-465. doi: 10.1016/j.ceb.2005.08.009

Lu, M., Jolly, M. K., Onuchic, J., and Ben-Jacob, E. (2014). Toward decoding the principles of cancer metastasis circuits. Cancer Res, 74, 4574-4587. doi: 10.1158/0008-5472.CAN-13-3367

Nieto, M. A. (2011). The ins and outs of the epithelial to mesenchymal transition in health and disease. Annu. Rev. Cell Dev. Biol. 27, 347-376. doi: 10.1146/annurevcellbio-092910-154036

Ohkubo, T., and Ozawa, M. (2003). The transcriptional factor Snail downregulates the tight junctio components indepndently of E-cadherin dowregulation. J. Cell Sci. 117, 1675-1685. doi: 10.1242/jcs.01004

Peinado, H., Olmeda, D., and Cano, A. (2007). Snail, Zeb and bHLH factors in tumour progression: an alliance against the epithelial phenotype? Nat. Rev. Cancer 7, 415-428. doi: 10.1038/nrc2131

Peiro, S., Escriva, M., Puig, I., Barbera, M. J., Dave, N., Herranz, N., et al. (2006). Snaill transcriptional repressor binds to its own promoter and controls its expression. Nucleic Acids Res. 34, 2077-2084. doi: 10.1093/nar/gkl141

Sánchez-Tillo, E., de Barrios, O., Siles, L., Cuatrecasas, M., Castells, A., and Postigo, A. (2011). beta-catenin/TCF4 complex induces the epithelial-to-mesenchymal transition (EMT)-activator ZEB1 to regulate tumor invasiveness. Proc. Natl. Acad. Sci. U.S.A. 108, 19294-19209. doi: 10.1073/pnas.1108977108

Siemens, H., Jackstadt, R., Hunten, S., Kaller, M., Menssen, A., Gotz, U., et al. (2011). miR-34 and SNAIL form a double negative feed-back loop to regulate epithelial to mesenchymal transitions. Cell Cycle 10, 4256-4271. doi: $10.4161 /$ cc.10.24.18552
Solanas, G., Porta-de-la-Riva, M., Agustí, C., Casagolda, D., Sánchez-Aguilera, F., Larriba, M. J., et al. (2008). E-cadherin controls beta-catenin and NFkappaB transcriptional activity in mesenchymal gene expression. J. Cell Sci. 121, 2224-2234. doi: 10.1242/jcs.021667

Stemmer, V., de Craene, B., Berx, G., and Behrens, J. (2008). Snail promotes Wnt target gene expression and interacts with beta-catenin. Oncogene 27, 5075-5080. doi: 10.1038/onc. 2008.140

Thompson, E. W., Newgreen, D. F., and Tarin, D. (2005). Carcinoma invasion and metastasis: a role for epithelial-mesenchymal transition? Cancer Res. 65, 5991-5995. doi: 10.1158/0008-5472.CAN-05-0616

Valenta, T., Hausmann, G., and Basler, K. (2012). The many faces and functions of $\beta$-catenin. EMBO J. 31, 2714-2736. doi: 10.1038/emboj.2012.150

Viñas-Castells, R., Frías, A., Robles-Lanuza, E., Zhang, K., Longmore, G. D., García de Herreros, A., et al. (2014). Nuclear ubiquitination by FBXL5 modulates Snail1 DNA binding and stability. Nucleic Acids Res. 42, 1079-1094. doi: 10.1093/nar/gkt935

Wong, M. C., Dobi, K. C., and Baylies, M. K. (2014). Discrete levels ofTwist activity are required to direct distinct cell functions during gastrulation and somatic myogenesis. PLoS ONE 9:e99553. doi: 10.1371/journal.pone.0099553

Wu, Y., Deng, J., Rychahou, P. G., Qiu, S., Evers, B. M., and Zhou, B. P. (2009). Stabilization of snail by NF-kappaB is required for inflammation-induced cell migration and invasion. Cancer Cell 15, 416-428. doi: 10.1016/j.ccr.2009.03.016

Yang, J., Mani, S. A., Donaher, J. L., Ramaswamy, S., Itzykson, R. A., Come, C., et al. (2004). Twist, a master regulator of morphogenesis, plays an essential role in tumor metastasis. Cell 117, 927-939. doi: 10.1016/j.cell.2004.06.006

Yook, J. I., Li, X. Y., Ota, I., Hu, C., Kim, H. S., Kim, N. H., et al. (2006). A WntAxin2-GSK3beta cascade regulates Snaill activity in breast cancer cells. Nat. Cell Biol. 8, 1398-1406. doi: 10.1038/ncb1508

Zhang, J., Tian, X. J., Zhang, H., Teng, Y., Li, R., Bai, F., et al. (2014). TGF-b-induced epithelial-to-mesenchymal transition proceeds through stepwise activtion of multiple feed-back loops. Sci Signal 7, ra91. doi: 10.1126/scisignal.2005304

Zheng, H., Shen, M., Zha, Y. L., Li, W., Wei, Y., Blanco, M. A., et al. (2014). PKD1 phosphorylation-dependent degradation of SNAIL by SCF-FBXO11 regulates epitelial-mesenchymal transition and metástasis. Cancer Cell 26, 358-373. doi: 10.1016/j.ccr.2014.07.022

Conflict of Interest Statement: The author declares that the research was conducted in the absence of any commercial or financial relationships that could be construed as a potential conflict of interest.

Received: 02 October 2014; paper pending published: 26 October 2014; accepted: 21 November 2014; published online: 12 December 2014.

Citation: García de Herreros A (2014) Epithelial to mesenchymal transition in tumor cells as consequence of phenotypic instability. Front. Cell Dev. Biol. 2:71. doi: 10.3389/ fcell.2014.00071

This article was submitted to Molecular and Cellular Oncology, a section of the journal Frontiers in Cell and Developmental Biology.

Copyright (C) 2014 García de Herreros. This is an open-access article distributed under the terms of the Creative Commons Attribution License (CC BY). The use, distribution or reproduction in other forums is permitted, provided the original author(s) or licensor are credited and that the original publication in this journal is cited, in accordance with accepted academic practice. No use, distribution or reproduction is permitted which does not comply with these terms. 